\title{
Surgical management of cervical mucocele associated with ranula in a dog
}

\begin{abstract}
A "2- year" old black coloured Labrador was presented at Institute Referral veterinary polyclinic with a history of swelling in the ventral mandibular region and inability to take food. On physical examination, a swelling was observed in the ventral neck and another was observed in the ventral aspect of the tongue close to the base. On fine needle aspiration of the swelling, contents were revealed straw coloured, the mucinous fluid that appeared ropey, confirmed the presence of saliva. A diagnosis of cervical mucocele associated with ranula was made. The mandibular and salivary glands were resected under general anaesthesia with atropine, butorphanol, diazepam, propofol, and isoflurane combinations. The sublingual salivary cyst below the tongue was incised. Oral mucocele (ranula) was corrected by deroofing and marsupialization was done. The muscles and subcutaneous tissue was sutured. The skin was opposed in routine fashion. The animal made an uneventful recovery without any complication under the postoperative antibiotics and 2-weeks semisolid diet regime.
\end{abstract}

Volume 5 Issue 3 - 2018

\section{Shivaraju S, Maiti SK, Kalaiselvan, Divya Mohan, Surendra DS, Ramith KR, Sangeetha P, Raghuvanshi PDS, Bindhuja BV, Naveen Kumar}

Division of Surgery, Indian Veterinary Research Institute, India

Correspondence: Swapan Kumar Maiti, Principal Scientist, Surgery Division, Indian Veterinary Research Institute, Izatnagar-243 |22, Uttar Pradesh, India, Tel +94|2049|69, Fax +91 581 2303284, Email swapanivri@gmail.com

Received: December 20, 2017 | Published: June 04, 2018

\section{Introduction}

Although salivary glands diseases are rare in canines, however, the occurrence of mucocele has been reported as less than 20 in 400 dogs. ${ }^{1}$ Salivary mucoceles are formed by the extravasation and accumulation of saliva in the subcutaneous tissue adjacent to ruptured salivary gland or duct system and are surrounded by granulation tissue induced by saliva. Dogs are more commonly affected than cats; however, all breeds are susceptible. Poodles, German Shepherds, Dachshunds, and Australian silky terriers are frequently affected. ${ }^{2-4}$ The sublingual and mandibular salivary glands are most commonly affected..$^{2-5}$ This condition can occur at any age.

\section{Case presentation}

A "2-year" old black coloured Labrador was presented at Institute Referral veterinary polyclinic with fluctuant swelling in the ventral

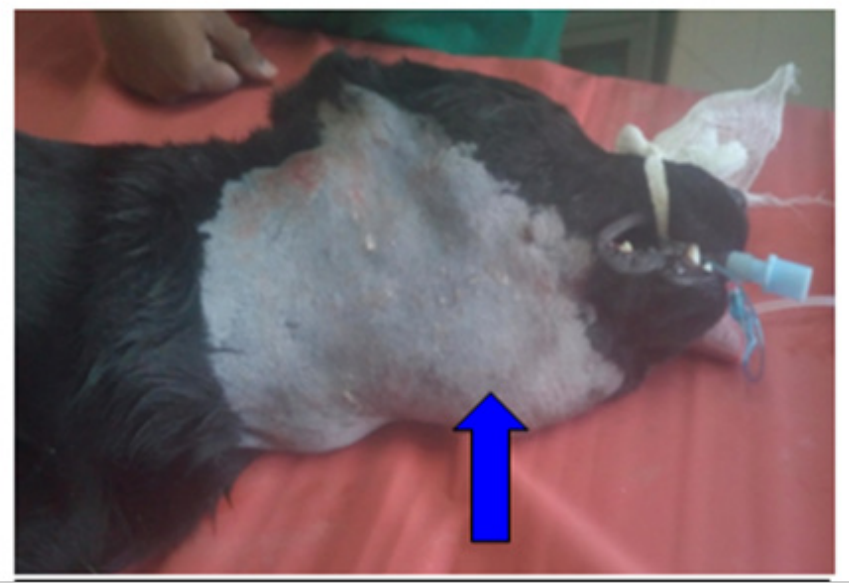

Figure I Anesthetized dog placed on the surgical table on lateral recumbency after aseptic preparation of surgical site showing salivary mucocele (arrow). inter-mandibular region, dysphagia, anorexia, excessive salivation and abnormal movements or protrusion of the tongue since 4 days. On physical examination soft, the non-painful swelling was located on the cranial ventral neck, lateral to the right side (Figure 1) and another was observed in the ventral aspect of the tongue close to the base. Left deviation of the tongue was observed (Figure 2). Palpation of the mass caused drooling of saliva from the mouth. Based on the history and clinical findings, cervical mucocele associated with oral mucocele or ranula was suspected. Paracentesis of the mass typically revealed a straw coloured, mucinous fluid that appeared ropey, confirmed the presence of saliva. Diagnosis of cervical mucocele with the involvement of right sublingual and submandibular salivary gland associated with ranula was made. The only drainage of the mucocele will not result in long-term resolution so; surgery was planned for deroofing the mucocele, followed by marsupialization and excision of mandibular and sublingual glands.

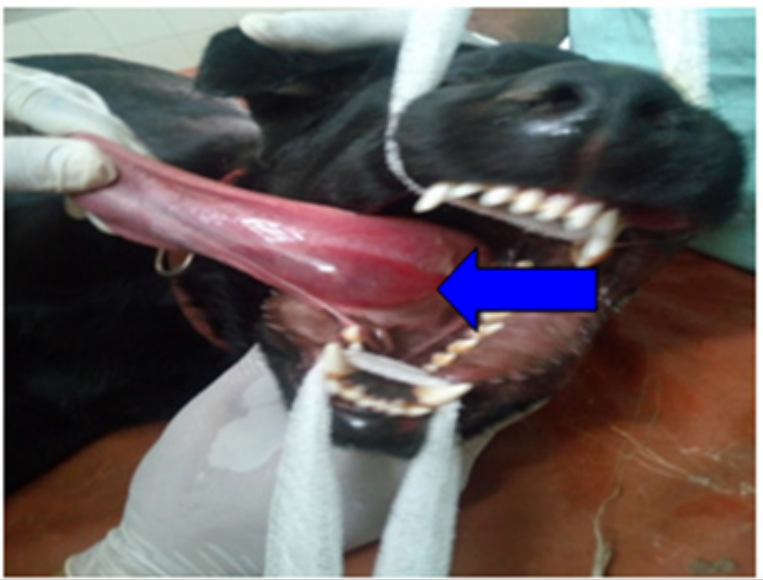

Figure 2 Ranula at the base of the tongue (arrow). 


\section{Surgical technique}

A guideline was followed as per Institute Animal Ethics for this clinical case during animal handling, anaesthesia and surgery. After premedication with atropine sulphate $0.04 \mathrm{mg} / \mathrm{kg}$, butorphanol $0.05 \mathrm{mg} / \mathrm{kg}$, diazepam $0.5 \mathrm{mg} / \mathrm{kg}$ and ceftriaxone $25 \mathrm{mg} / \mathrm{kg}$, anaesthesia was induced with propofol $4 \mathrm{mg} / \mathrm{kg}$ and maintained with $2 \%$ isoflurane with oxygen. The site was prepared for aseptic surgery. The animal was secured in left lateral recumbency. The right mandibular and sublingual salivary glands both were removed by making an incision over the mandibular gland region. Through skin, subcutaneous tissue, platysma muscle and capsule of the mandibular salivary gland were identified and incised to expose the gland. Dissection then proceeded cranially along the mandibular duct to expose the monostomatic and polystomatic portions of the sublingual gland. The mandibular sublingual gland duct complex was dissected as far

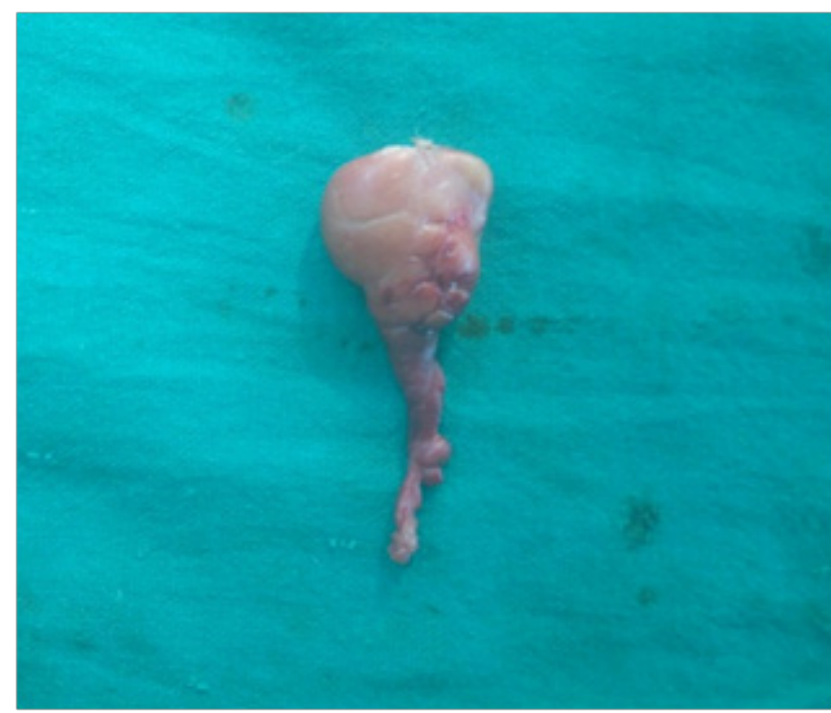

Figure 3 Surgically excised mandibular sublingual gland duct complex.

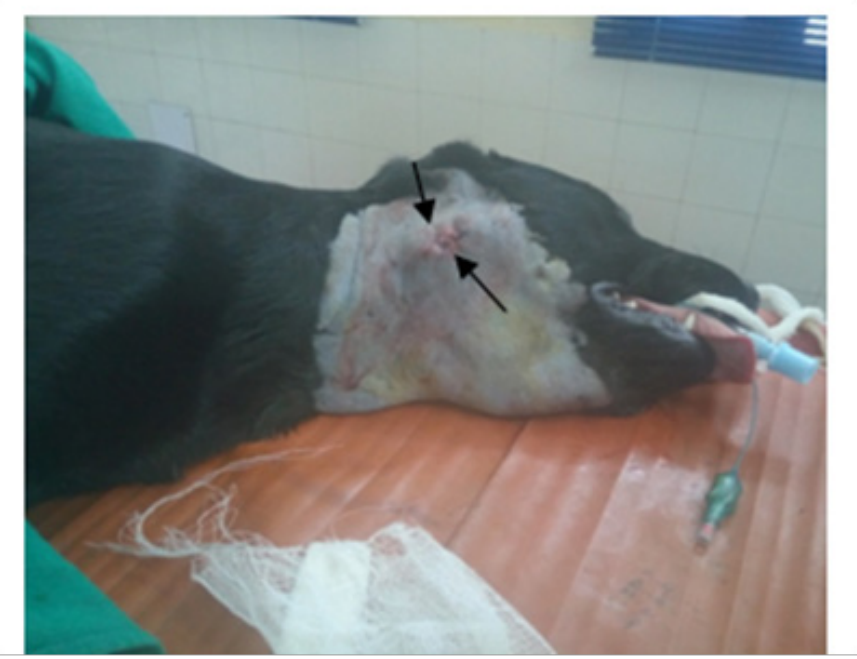

Figure 4 Surgical site after skin suture. cranially as possible, then was ligated and removed (Figure 3). The platysma muscle, subcutaneous tissue and capsule of the gland were sutured using absorbable suture diameter of 3.5 metrics. The skin was sutured in a routine manner (Figure 4). Oral mucocele (ranula) corrected by removing the mucosa over the dorsal portion of the swelling (deroofing). Marsupialization was done by suturing the interior layer of the mucocele to the oral mucosa using absorbable suture. This allows the mucocele to remain open and drain into the mouth. The owner was directed to clean the animal's mouth with chlorhexidine mouthwash and feed the dog soft food for 2 weeks. The animal was prescribed antibiotics and anti-inflammatory agents for five days postoperatively. No postoperative complication includes wound dehiscence, salivary leakage, stitch abscess was recorded. Recovery was normal (Figure 5). No evidence of xerostomia or other complications were encountered.

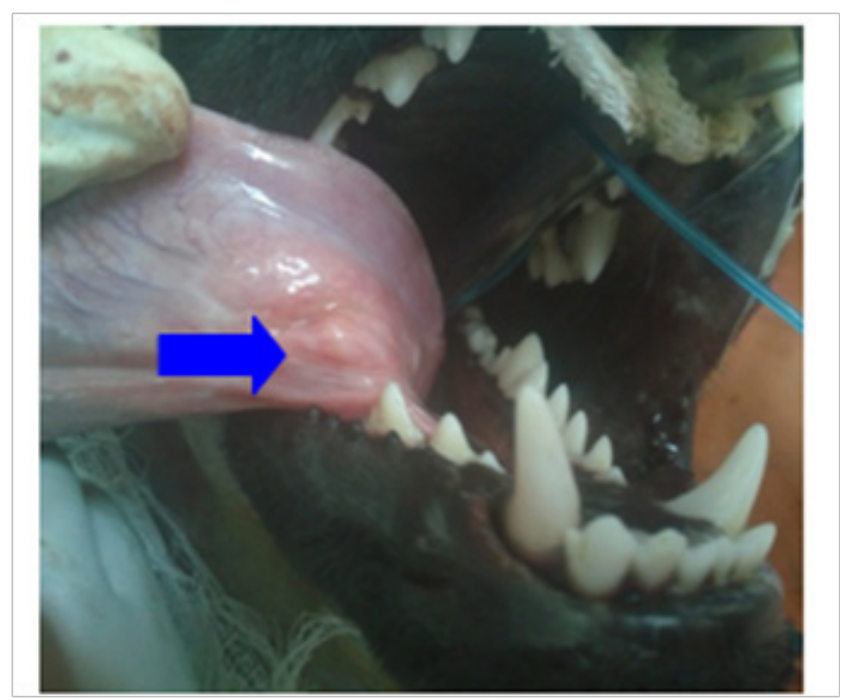

Figure 5 The complete healing of marsupialized ranula at the base of the tongue after 10 days of surgery (arrow).

\section{Discussion}

Salivary glands disorders are rare in canines, mucoceles are considered as the most common condition. Mucoceles are classified by their location as cervical, sublingual (ranula), pharyngeal and zygomatic mucoceles. Most prevalent is the cervical mucocele. Trauma to head or neck in the form of a choke chain, salivary gland or duct foreign bodies, sialoliths, dirofilariasis and neoplasia can cause salivary mucoceles; however, most cases are idiopathic. ${ }^{2,6}$ Oral mucocele (ranula) can occur after mandibulectomy surgery. Clinical signs of mucoceles vary according to their location which includes fluctuant, non-painful swelling in the cranial ventral cervical area (cervical mucocele), dysphagia, anorexia (ranula), inspiratory stertor and dyspnea (pharyngeal mucocele) and exophthalmos, divergent strabismus, and a fluctuant swelling in the orbital area (zygomatic). In most cases, salivary mucoceles are not a diagnostic challenge, history, clinical signs, paracentesis and histopathologic findings will give the confirmatory diagnosis. The present case was diagnosed as cervical mucocele associated with ranula. Ultrasound, computed tomography or positive contrast sialography can be performed these are usually not 
necessary but may be indicated in complicated or atypical cases. Nonsurgical treatment of mucocele lies in the misbelieve that mucocele is a true cyst with secretory lining but it is not a true cyst since it does not have any secretory lining and contain granulation tissue lining which originates from inflammatory reaction to free saliva.? In spite of location, the definitive treatment of a salivary mucocele involves excision of the offending or damaged salivary glands. Marsupialization alone not recommend for long-term resolution. So in the present case marsupialization was done along with excision of mandibular and sublingual glands. Recurrence of the mucocele is rare after surgical treatment but may indicate incomplete removal of the affected salivary tissue, or that the incorrect gland was removed.

\section{Conclusion}

The clinical case was diagnosed as salivary mucocele associated with ranula. The mandibular sublingual gland duct complex was ligated and removed. Oral mucocele (ranula) was corrected by deroofing and marsupialization was done. The animal made uneventful recovery without any complication under the postoperative antibiotics and 2-weeks semisolid diet regime.

\section{Acknowledgments}

Authors are highly thankful to Director and Incharge, Veterinary Polyclinics, Indian Veterinary Research Institute (IVRI), UttarPradesh, India providing necessary facilities to carry out the present work.

\section{Conflict of interest}

The author declares no conflict of interest.

\section{References}

1. Smith MM. Oral and salivary gland disorders. In: Etinger SJ, Feldman EC, editors. Textbook of veterinary internal medicine. 6th ed. USA: Elsevier; 2005. pp. 1290-1297.

2. Hedlund CS, Fossum TW. Surgery of the oral cavity and oropharynx. In: Fossum TW, editor. Small animal surgery. 3rd ed. Mosby, St. Louis, Mo, USA: Elsevier; 2007. pp. 339-372.

3. Dunning D. Oral cavity. In: Slatter D, editor. Textbook of small animal surgery.3rd ed. Saunders, Philadelphia, PA, USA; 2003. pp. 553-572.

4. Knecht CD. Salivary glands. In: Bojrab MJ, editor. Current techniques in small animal surgery. 4th ed. Baltimore, Md, USA: Williams \& Wilkins; 1998. pp. 183-186.

5. Tobias KM. Manual of small animal soft tissue surgery. Ames, Iowa, USA: Wiley-Blackwell; 2010.

6. Bellenger CR, Simpson DJ. Canine sialocoeles-60 clinical cases. $J$ Sm Anim Practice. 1992;33(8):376-380.

7. Yasonu $\mathrm{H}$, Nagai $\mathrm{H}$, Ishimura $\mathrm{Y}$, et al. Salivary mucocele in a laboratory beagle. J Toxicol Pathol. 2011;24(2):131-135. 